\title{
The Important in Nutrition in Pregnancy
}

\author{
Deborah Garida Nunes* and Maria Gisele dos Santos \\ Federal University of Paraná, Brazil \\ *Corresponding Author: Deborah Garida Nunes, Federal University of Paraná, \\ Brazil. \\ DOI: $10.31080 /$ ASNH.2022.06.1011
}

Received: January 04, 2022

Published: February 21, 2022

(C) All rights are reserved by Deborah Garida

Nunes and Maria Gisele dos Santos.

\begin{abstract}
The human being has around 100 trillion cells and of these, 50 billion are renewed daily. Each cell uses numerous nutrients to promote its proper functioning. The promotion of a perfect cellular functioning allows the organs the expected functional execution $[1,2]$. Medicine has demonstrated in recent centuries the correlation between nutritional imbalances and various diseases associated with them. The relationship between human beings and food dates to antiquity [3,4]. Thus, it is understood that nutrition is essential for the existence of living beings. Nutrition is the science that studies food and nutrients, analyzing its action, interaction and balance related to health and disease [5]. Functional nutrition consolidates genetic, physiological and scientific knowledge, taking into account the emotional and environmental aspects of the human being to promote health in its integral form [6,7]. Here, it is worth mentioning that dietotherapeutic care involves everything from cellular nutrition to stress factors, emotional changes, exposure to pesticides and environmental pollutants $[8,9]$.
\end{abstract}

Keywords: Nutrition; Pregnancy; Healthy; Eating Habits

\section{Nutritional care for a healthy pregnancy}

Much is said about a healthy diet during pregnancy, but it is known that eating habits and even the use of medications can alter cell nutrition and impair the development of pregnancy. For example, the use of oral contraceptives can promote the reduction of stocks of various minerals and vitamins such as folic acid, riboflavin, pyridoxine, cobalamin, vitamin $\mathrm{C}$ e, and minerals such as magnesium, selenium and zinc $[10,11]$. Such nutritional deficiencies can lead to complications during pregnancy. Cyanocobalamin deficiency increases homocysteine concentration and may lead to miscarriage due to hyper coagulability [12].

In addition, the literature describes those women who had babies with fetal neural tube (DTN) defects had serum levels of folic acid and erythrocytic cobalamin, slightly reduced when compared to women in the control group, associated with increased serum homocysteine levels. According to the studies, they are independent risk factors for TD, low levels of folate serum and cobalamin [13].
Neural tube defects or malformations are anencephaly, hydrocephalus, meningomyelocele and spina bifida. Such malformations are directly linked to hyperhomocysteinemia and reduced levels of vitamin B12 and folic acid [14].

Neural tube closure occurs in the first weeks of pregnancy, and it is currently that the body uses nutrient reserves, especially B-complex vitamins such as B9 and B12. Therefore, the stocks of these nutrients in the pre-gestational period should be satisfactory $[15,16]$.

Some studies reinforce that the joint supplementation of vitamins and minerals and doses between 400 and $800 \mathrm{mcg}$ of folic acid have more efficiency for the prevention of DTN than folic acid supplementation alone. This is due to nutritional imbalances that its use isolated in high doses can cause in other nutrients such as zinc deficiency, vitamin A and B12, in addition to vitamin B6 [17].

Thus, it is understood that the nutritional conditions of women for pregnancy come before conception. There is already consen- 
sus that the first thousand children's day, between conception and the end of the second year of the child's life, shape the brain and metabolic development of human beings [18]. Thus, researchers suggest that women make a metabolic program that covers their lifestyle, such as avoiding tobacco consumption, alcoholic beverages, high intake of saturated and trans fats, sleep quality, exposure to the sun, consuming healthier foods and practiced regular physical activity [19].

\section{Metabolism in Pregnancy}

The gestational period is marked by an intense anabolic process. Weeks after conception, the placenta is already formed and begins to secrete important hormones related to the metabolism of various nutrients. These alter maternal metabolism, promote fetal growth, prepare the mother for labor and lactation [20].

Metabolic adaptations resulting from pregnancy are essential to ensure the growth and proper development of the fetus, provide sufficient energy and nutrients until its birth and control maternal stocks of nutrients and energy during pregnancy, delivery and lactation $[21,22]$.

Of the maternal physiological changes, what stands out most is the hemodilution, which increases its total blood volume by 40 to $50 \%$. Such adaptation is due to the supply to protect the mother and baby when in supine position, in addition to preventing blood loss during childbirth.

In pregnancy, a reduction in the plasma level of amino acids is observed due to the high fetal demand. The pregnant woman saves this type of substrate for fetal synthesis and there is an adjustment in lipid metabolism. The baby uses about $80 \%$ glucose for energy production, not using circulating fatty acids.

The hormones involved are GH (placental), epinephrine, placental lactogen hormone (hPL), and others that increase for lipolysis and use of pregnant women as energy, raising plasma levels of cholesterol, fatty acids, TG and phospholipids. As the mother preserves plasma glucose for the fetus, her fasting glucose is 15 to $20 \mathrm{mg}$ lower than in the pre-gestational period. For this to be possible, during this period, a peripheral resistance to insulin is observed. During feeding, maternal hyperinsulinemia suppresses lipolysis and ketogenesis and increases amino acid uptake. Promoting an adjustment in fat storage and tissue protein synthesis. The hormones involved in this mechanism are progesterone, placental GH, lactogenic hormones, glucagon, cortisone and estrogen $[23,24]$. Some hormones affect a woman's quality of life during pregnancy. Thus, progesterone increases appetite in the first half of pregnancy, reducing uterine contractility and intestinal motility. Estrogen plays hydroscopic action on tissues, favoring its elasticity and edema. It also dilutes serum proteins and favors skin hyperpigmentation and can reduce appetite in the second half of pregnancy. Human placental lactogen (hPL) has mammogenic action and reduces insulin sensitivity during pregnancy $[25,26]$.

Due to all these changes, the mother's nutritional and energy demand becomes very high. Thus, the two second quarters are marked by the increase in the caloric requirement to meet all this demand. It is also worth mentioning that gene expression is dependent on nutrients such as omega-3, zinc, chromium, vitamin D, magnesium and others $[27,28]$.

At the beginning of pregnancy, there is no caloric increase. There is then, from the second trimester, an increase in the mother's metabolic rate until the third trimester of approximately $300 \mathrm{kcal} /$ day, increasing the risk of ketosis when food deprivation occurs in the mother $[29,30]$.

It is important to identify whether the pregnant woman is underweighting or overweight at the beginning of pregnancy, to enable appropriate interventions to correct nutritional imbalances. The low weight of the pregnant woman increases the risk of preterm and low birth weight and maternal anemia. Overweight and maternal obesity increase the risk of cesarean section, difficulty in losing weight after childbirth, having overweight children, gestational diabetes and hypertension that can compromise the life of the baby and the mother [31].

Regarding satisfactory weight gain, eutrophic pregnant women are expected to increase from 15 to $20 \%$ of her pre-gestational weight. According to the Institute of Medicine [31], the recommended weight gain is reported in table 2 [32].

In twin pregnancies, individualized evaluation is necessary. In any case, a weight gain of around $2.7 \mathrm{~kg}$ per month is recommended from the twentieth gestational week (VITOLO, 2008).

\section{Pregnant Woman's Food}

From conception to breastfeeding, the baby is totally dependent on the feeding of the pregnant woman. This is because during pregnancy, the baby feeds on nutrients absorbed and metabolized by the mother. In addition, the pregnant woman's eating habits still di- 


\begin{tabular}{|c|c|c|c|}
\hline & First quarter & Second quarter & Third quarter \\
\hline $\begin{array}{c}\text { Physiological } \\
\text { changes }\end{array}$ & $\begin{array}{l}\text { 10-25\% physiological increase } \\
\text { in functions and metabolism. } \\
\text { Increased heart rate. } \\
\text { Thickening of the muscle fibers } \\
\text { of the uterus, causing pressure } \\
\text { on the bladder on the right } \\
\text { side. } \\
\text { Loss of concentration and } \\
\text { increased drowsiness caused } \\
\text { by progesterone. }\end{array}$ & $\begin{array}{c}\text { Relaxation of the Muscles of the TGI causes } \\
\text { lower secretion of digestive enzymes, } \\
\text { leading to delay in gastric emptying and } \\
\text { constipation. } \\
50 \% \text { increase in blood volume. } \\
\text { Increased respiratory rate. } \\
\text { Baby growth pushes the ribs and pelvis. } \\
\text { Insulin resistance. }\end{array}$ & $\begin{array}{l}\text { Progesterone causes hypotonia of } \\
\text { the isophane inferior sphincter } \\
\text { Increased pressure of the uterus on } \\
\text { the stomach. } \\
\text { Changes already related in the } \\
\text { second quarter, but it is noted more } \\
\text { markedly. }\end{array}$ \\
\hline $\begin{array}{l}\text { Common } \\
\text { symptoms }\end{array}$ & $\begin{array}{l}\text { Heartburn, nausea and vomi- } \\
\text { ting, eructation and bloating. }\end{array}$ & $\begin{array}{l}\text { Breast paresthesia and Mastalgia, colostrum } \\
\text { production, gum slur, gastroesophageal } \\
\text { reflux and heartburn, dyspnea, frequency } \\
\text { and urgency to urinate, need for rest and } \\
\text { drowsiness, mmss edema and LLLl, discom- } \\
\text { fort to walk, increased hunger. }\end{array}$ & $\begin{array}{l}\text { All related in the second quarter } \\
\text { and may be more pronounced at } \\
\text { this stage. }\end{array}$ \\
\hline
\end{tabular}

Table 1: Summary of physiological changes during pregnancy.

\begin{tabular}{|c|c|c|c|}
\hline $\begin{array}{c}\text { Nutritional status } \\
\text { Pre-gestational }\end{array}$ & $\begin{array}{c}\text { Total weight gain in } \\
\text { the 1st quarter (kg) }\end{array}$ & $\begin{array}{c}\text { Weekly weight gain rate in the second } \\
\text { and third trimesters of pregnancy (kg) }\end{array}$ & Total weight gain (kg) \\
\hline $\begin{array}{c}\text { Pre-gestational BMI or in the first } \\
\text { trimester of < 20 }\end{array}$ & 2,3 & $0,521(0,453-0,589)$ & 12.5 to $18 \mathrm{~kg}$ \\
\hline $\begin{array}{c}\text { Pre-gestational BMI between 20 } \\
\text { and 24.9 }\end{array}$ & 1,6 & $0,406(0,362-0,453)$ & 11.5 to $16 \mathrm{~kg}$ \\
\hline $\begin{array}{c}\text { Pre-gestational BMI between 25 } \\
\text { and 29.9 }\end{array}$ & 0.3 to 0.9 & $0,272(0,226-0,317)$ & $71.5 \mathrm{~kg}$ \\
\hline Pre-gestational BMI > 30 & 0 & $0,226(0,181-0,272)$ & 6 to $7 \mathrm{~kg}$ \\
\hline
\end{tabular}

Table 2: Recommended weight gain according to gestational trimesters.

rectly influence the baby's variety, quality and even taste, because the placenta can interfere with the baby's taste and smell $[29,30]$.

It is important to note that during pregnancy, women should not diet restrictively or lose weight during this period. Researchers have demonstrated that this type of conduct can generate smaller babies with metabolic alterations. Thus, the diet should be as healthy and varied as possible, including fresh vegetables and fruits, grains and seeds, as well as whole grains, lean protein sources and healthy fats. It is important to consume meals every 2 and a half to 3 hours, in smaller amounts and chew the food very well to facilitate digestion and avoid gastric discomforts such as reflux, heartburn, eructation and gases, in addition to constipation $[22,28,30]$.

Meals should include all food groups such as complex or whole carbohydrate, legumes, vegetables and fruits, AVB proteins and mono and polyunsaturated fats. This care makes it possible to intake different nutrients that complement each other and provide sufficient substrate for the nutrition of the mother and baby to be adequate [33].

Regarding the distribution of macronutrients, calculated under the total energy value (VET), it is recommended 45 to $65 \%$ of carbohydrates, 15 to $20 \%$ of proteins (adjusting to $10 \mathrm{~g}$ or $1.1 \mathrm{~g} / \mathrm{kg}$ of pre-gestational weight/day, not exceeding the intake of $71 \mathrm{~g}$ per day) and 20 to $35 \%$ lipids [2].

The American Dietetic Association (ADA) does not guide diets that have amounts of less than $130 \mathrm{~g} /$ day of carbohydrates, harming maternal and child health. As for proteins, high biological value (AVB) should be prioritized and their distribution between $10 \%$ and $35 \%$ of VET AL In addition, the intake of saturated fats 
should be less than $7 \%$ of total lipids and cholesterol, less than $200 \mathrm{mg} /$ day. The recommendations of vitamins, minerals and fibers (20 - 35g/day or $14 \mathrm{~g}$ for every $1000 \mathrm{kcal}$ ) are similar for pregnant women who have mgd or not. It is important to note that the energy recommendation should promote adequate weight gain and restrictive diets are discouraged and may lead to ketonuria [2].

The RDA recommends a daily intake of $175 \mathrm{~g}$ /day of carbohydrates for pregnant women and $210 \mathrm{~g} /$ day for lactating women. Protein consumption of $1 \mathrm{~g} / \mathrm{kg} /$ day (calculated on pre-gestational or acceptable weight) is recommended with an additional $1 \mathrm{~g} /$ day in the first half, $9 \mathrm{~g} /$ day in the second trimester and $31 \mathrm{~g} /$ day in the third trimester. Of these, it was recommended to intake at least $50 \%$ of protein of high biological value [30].

Good quality proteins or AVB are those from animal origin such as meat and poultry, dairy products, eggs and fish. According to IOM, these proteins are the source of the nine essential amino acids (phenylalanine, histidine, isoleucine, leucine, lysine, methionine, threonine, tryptophan and valine) and, for this reason, are called AVB or "complete proteins". Plant proteins such as those present in legumes, grains, nuts, seeds and some vegetables do not include all essential amino acids, so they are called "incomplete proteins" [30].

To the so-called simple or complex carbohydrates, such nomenclature was related to the speed of digestion and availability of seeric glucose. Being the simple carbohydrates of rapid digestion and elevation of glycemia and complex, being of slower digestion and gradual elevation of glycemia. Currently, it is known that the structure of the molecule influences digestion time and glucose elevation [33].

However, postprandial glycemia is influenced by the time of metabolization of carbohydrates, the availability of serum glucose, insulin secretion and its peripheral tissue sensitivity. So, the glycemic response depends on the amount and glycemic index of the carbohydrate ingested [34].

The intrinsic factors that influence the glycemic response of carbohydrates may be their physical form (juice or fruit), the type of starch, maturation, the type of preparation (fried, cooked, roasted), among others [30].
There are other factors that contribute to the glycemic response and that prevent the accuracy of this calculation such as age, body composition, mealtimes, chewing, existence of peripheral resistance to insulin, intestinal microbiota and genetic individuality, among others $[27,28]$.

In any case, two mechanisms can impact to reduce the glycemic response in meals, such as modulating the rate of absorption of carbohydrates including more viscous fibers and mono or polyunsaturated fats and increasing insulin secretion through protein intake [5].

The concentration and distribution of carbohydrates throughout the day can contribute to better glycemic control. However, this strategy should be individualized, considering the eating habits, tests and tolerance of the pregnant woman. Thus, to control the glycemic load of the diet, fractionation and reduction of carbohydrate volume are guided, maintaining fixed schedules for meals $[2,4]$.

The fractionation of meals allows the pregnant woman not to present hypoglycemia, nausea and even emesis, besides regulating the hunger-satiety axis. Establishing mealtimes allows the body to organize itself to provide digestive enzymes and hormones, optimizing the digestive process and avoiding discomfort [34].

Due to the increase in free fatty acids resulting from pregnancy, one should consider an intake of up to $30 \%$ of vet of total fats, limiting the intake of saturated fats to $10 \%$ and discourage the intake of trans fats. In dyslipidemia, it is recommended to limit the intake of cholesterol to $200 \mathrm{mg} /$ day. However, fat restriction is not recommended due to the fetal process of myelinization, which may compromise its neurological development [15].

Regarding, polyunsaturated long-chain n-3 (omega-3) fatty acids (LCPUFA) are essential in mammalian health. These facts are present in fish and flaxseed oil, and fish oil has the most efficient form of LCPUFA [4].

LCPUFA measures physiological processes such as angiogenesis, immunity, inflammatory response, among other cellular and molecular functions that impact health and disease. Eicosapentae- 
noic acid, 22: 5n-3 (EPA) and Docosaexaenoic acid, 22: 6n-3 (DHA) comprise part of cellular signaling. DHA is part of the structure and function of the cell membrane $[7,9]$.

Researchers report that the diet rich in refined foods have a low content of PUFAs n-3, leading individuals to an increased risk of diseases $[10,17]$.

Thus, inadequate maternal intake of DHA and EPA can impair the baby's growth, exposing it to risks of cognitive decline, inflammatory processes, cardiovascular disease, behavioral changes and mental stress in adulthood (K).

The study by Helland., et al. (2003) suggested that maternal supplementation of omega-3 polyunsaturated fatty acids such as DHA and AA during pregnancy and lactation influenced children's intelligence. Although there are positive results of omega-3 supplementation during pregnancy, we must remember that adequate and individualized feeding is essential in this period, directly influencing the effects of supplementation.

An observational study ( $\mathrm{N}=11,875)$ conducted by [15] demonstrated that the higher maternal consumption of seafood during the gestational period had influenced the fine motor skills, behavior, verbal intelligence and social development of children up to 8 years of age.

It is already clear the importance of the consumption of omega-3 fatty acids during pregnancy - both for the health of the mother and baby. Several well-delineated research proves these benefits.

Thus, a study conducted by Bisgaard., et al. (2016) with 736 pregnant women, related omega-3 supplementation to reduced risk of allergies, asthma and respiratory tract infections in infants. The researchers administered $2.4 \mathrm{~g}$ of omega 3 (55\% EPA and 37\% DHA) per day from the third trimester of pregnancy, suspending its administration in the last gestational week.

These results reinforce the importance of the quality of fats that will be part of the diet of pregnant women. In addition to this important factor, it is necessary to take into account the other nu- trients that will be part of the diet of pregnant women, since synergy and nutritional balance are more relevant than an isolated nutrient.

Therefore, the data cited here reinforce the importance of the quality of diet fats in the gestational period. In addition, the other nutrients that will be part of the feeding of pregnant women should be considered to provide synergy and nutritional balance.

The food sources of LCPUFA (n-3) are cold- and deep-water fish, seafood and seeds. Some fish have higher amounts of omega-3 (n3) per serving, so in $60 \mathrm{~g}$ of these we have anchovy with 1,200mg, wild salmon with $590 \mathrm{mg}$, sardines with $556 \mathrm{mg}$, trout with $550 \mathrm{mg}$ and tuna with $488 \mathrm{mg}$. Similarly, for seafood, mussels have $443 \mathrm{mg}$, oysters 390mg, crab 234mg, scallops 206mg and shrimps 178mg (Mozaffarian; Rimm, 2006)

\section{Conclusion}

The alert is for pregnant women, because the methyl Mercury exceeds the placenta, exposing the fetus to the risk of neurodevelopmental changes. It is noteworthy that fish and seafood suffer contamination of methyl Mercury related to environmental contamination, predatory nature and longevity of the species. For example, swordfish, sharks are larger animals and live longer, have higher concentrations of mercury, while smaller animals such as molluscs and salmon have lower concentrations of this metal (Stem, 2000; Dhhs-Us, 2021). The recommendation for fish consumption for pregnant or lactating women according to the Dietary Guidelines for Americans (2015-2020) is 2 to 3 parts per week, choosing fish with low mercury content. Another orientation is to prefer fresh fish to canned, avoid fried foods and prefer healthier preparations, such as grilled or stewed (DHHS-US, 2015; Brazil, 2014).

\section{Bibliography}

1. American Diabetes Association (ADA). Nutrition recommendations and interventions for diabetes. "Gestational diabetes mellitus". Diabetes Care 27.1 (2004): S88-90.

2. American Diabetes Association (ADA). "Nutrition recommendations and interventions for diabetes". Diabetes Care 30.1 (2008): S61-78. 
3. American Diabetes Association (ADA). "Standards of medical care in diabetes-2007". Diabetes Care 30.1 (2007): s4-s41.

4. American Dietetic Association (ADA). "Position of the American Dietetic Association: use of nutritive and Nonnutritive sweeteners". Journal of the American Dietetic Association 104.2 (2004): 255-275.

5. Amiri FN., et al. "Hygiene practices and sexual activity associated with urinary tract infection in pregnant women". La Revue de Santé de la Méditerranée orientale 15.1 (2009).

6. Antilla H., et al. "Viscosity of beta-glucan in oat produtcts". Journal of the Science of Food and Agriculture 13 (2004): 8087.

7. Aranha FQ., et al. "The role of vitamin C on organic changes in the elderly". Revista de Nutrição, Campinas 13.2 (2000): 89-97.

8. Brazilian Neurology Association (ASBRAN). "Caffeine intake by pregnant women is associated with adverse outcomes at birth". The American Journal of Clinical Nutrition 108 (2018): 1301-1308.

9. Au KS., et al. "Finding the genetic mechanisms of folate deficiency and neural tube defects-Leaving no stone unturned". American Journal of Medical Genetics 173.11 (2017): 3042-3057.

10. Augustin LSA. "Post-prandial glucose and insulin responses of hommus alone or combined with carbohydrate food: a doseresponse study". Nutrition Journal 15.1 (2016): 1-8.

11. Baig-ansari N., et al. "Anemia prevalence and risk factors in pregnant women in an urban area of Pakistan". The Food and Nutrition Bulletin 29.2 (2008): 132-139.

12. Bailey LB and Berry RJ. "Folic acid supplementation and the occurrence of congenital heart defects, orofacial clefts, multiple births, and miscarriage". The American Journal of Clinical Nutrition 81 (2001): 1213S-1217S.

13. Bennett M. "Vitamin B12 deficiency, infertility and recurrent fetal loss". The Journal of Reproductive Medicine 46.3 (2001): 209-212.
14. Bisgaard H., et al. "Fish Oil-Derived Fatty Acids in Pregnancy and Wheeze and Asthma in Offspring". The New England Journal of Medicine 375 (2016): 2530-2539.

15. Biswas AB., et al. "Evaluation of vitamin A status during pregnancy". Journal of Indian Medical Association 98 (2000): 525529.

16. Blumfield ML., et al. "Systematic review and meta-analysis of energy and macronutrient intakes during pregnancy in developed countries". Nutrition Reviews 70.6 (2012): 322-336.

17. Bordeleau M., et al. "From Maternal Diet to Neurodevelopmental Disorders: A Story of Neuroinflammation". Frontiers in Cellular Neuroscience 14 (2021): 612705.

18. Bourre JM. "Dietary omega-3 fatty acids for women". Biomed Pharma 61 (2007): 105-112.

19. Bradbury J. "Docosahexaenoic acid (DHA): An ancient nutrient for the modern human brain". Nutrients 3 (2011): 529-554.

20. Brantsaeter AL., et al. "Intake of probiotic food and risk of preeclampsia in primiparous women: the Norwegian Mother and Child Cohort Study". American Journal of Epidemiology 174.7 (2011): 807-815.

21. Brazil. "Attention to low-risk prenatal care". 1. Ed. rev. Brasília: Editor of the Ministry of Health (2013).

22. Brazil. "Ministry of Health. Department of Health Care. Department of Primary Care. Food guide for the Brazilian population/Ministry of Health, Health Care Secretariat, Department of Primary Care. - 2. ed., 1. Reimpr. Brasília: Ministry of Health 156 (2014): 978-85-334-2176-9 ISBN

23. IBGE. "Analysis of Personal Food Consumption in Brazil 20082009" (2011).

24. Institute of Medicine (IOM). "Dietary reference intakes for energy, carbohydrate, fiber, fat, fatty acids, cholesterol, protein, and amino acids". Washington (DC): National Academy Press. Journal of the American Dietetic Association (2005). 
25. James A., et al. "Folic Acid Supplementation and Pregnancy: More Than Just Neural Tube Defect Prevention". Reviews In Obstetrics and Gynecology 4.2 (2011).

26. Jeziorek M., et al. "The influence of diet on gastrointestinal Candida spp. Colonization". Rocz Panstw Zakl Hig 70.2 (2019): 195-200.

27. Junior AG., et al. "Candidiasis Vaginal: a matter of health education/Vaginal Candidiasis: a matter of education in health". Brazilian Journal of Health 2.2 (2014).

28. Kabaran S and Besler HT. "Do fatty acids affect fetal programming?" Journal of Health, Population and Nutrition 33 (2015):

14.

29. Khaled K., et al. "Perceived stress and diet quality in women of reproductive age: a systematic review and meta-analysis". Nutrition Journal 19.1 (2020): 92.

30. Kumamoto CA., et al. "The gut, the bad and the harmless: Candida albicans as a commensal and opportunistic pathogen in the intestine". Current Opinion in Microbiology 56 (2020): 7-15.

31. López-moreno A and Aguilera M. "Review Probiotics Dietary Supplementation for Modulating Endocrine and Fertility Microbiota Dysbiosis". Nutrients 12 (2020): 757.

32. Maeda SS., et al. "Recommendations of the Brazilian Society of Endocrinology and Metabology (SBEM) for the diagnosis and treatment of hypovitaminosis D". Arquivos Brasileiros de Endocrinologia and Metabologia (2014): 58-59.

33. Mafra D and Cozzolino SMF. "Importance of zinc in human nutrition”. Revista de Nutricao Campinas 17.1 (2004): 79-87.

34. Malachias MVB., et al. "7th Brazilian Guideline on Hypertension: Chapter 9 - Arterial Hypertension in pregnancy". Arquivos Brasileiros de Cardiologia, São Paulo 107.3-3 (2016): 49-52.

\section{Assets from publication with us}

- Prompt Acknowledgement after receiving the article

- Thorough Double blinded peer review

- Rapid Publication

- Issue of Publication Certificate

- High visibility of your Published work

Website: www.actascientific.com/

Submit Article: www.actascientific.com/submission.php Email us: editor@actascientific.com

Contact us: +919182824667 